\title{
Focal type of the Takotsubo (stress) Cardiomyopathy
}

\author{
Marcos Danillo Peixoto Oliveira*, Ednelson Cunha Navarro, Rafaella Pinto Ferraz, Glenda Alves de Sá, Helio \\ Jose Castello Júnior and Marcelo José de Carvalho Cantarelli
}

Department of Interventional Cardiology, Hospital Regional do Vale do Paraíba, Brazil

Submission: November 30, 2018; Published: January 24, 2019

*Corresponding author: Marcos Danillo Peixoto Oliveira, Department of Interventional Cardiology, Hospital Regional do Vale do Paraíba, Avenida Tiradentes, 280, Jardim das Nações, Taubaté - SP, Brazil

\begin{abstract}
Takotsubo (stress) cardiomyopathy is characterized by transient systolic and diastolic left ventricular dysfunction with a variety of wallmotion abnormalities. it predominantly affects elderly women and is often preceded by emotional and/or physical triggers but has also been reported without evident trigger(s). The clinical presentation, electrocardiographic findings and cardiac biomarker profiles are often similar to those of Acute Coronary Syndromes (ACS). We report herein an interesting case of the most rare (focal) type of the Takotsubo (stress) cardiomyopathy.
\end{abstract}

Keywords: Cardiomiopathy, left ventricular; Electrocardiographic; Acute coronary syndromes; Brain-heart axis, Cigarrete smoker and alcoholic, Sincopal episodes, Dynamic alterations, Antero-lateral,

\section{Introduction}

First described in Japan in 1990 [1], Takotsubo (stress) cardiomyopathy (TSC) is characterized by transient systolic and diastolic Left Ventricular (LV) dysfunction with a variet of wallmotion abnormalities [2,3]. Its name derives from the Japanese word takotsubo ("octopus pot"), describing the marked ballooning of the LV apex [4].

Generally recognized as a benign disorder, it predominantly affects elderly women and is often preceded by emotional and/or physical triggers, [5] but has also been reported without evident trigger(s). The clinical presentation, electrocardiographic findings and cardiac biomarker profiles are often similar to those of Acute Coronary Syndromes (ACS).

Although the causes of TSC remain unknown, the role of the brain-heart axis in the pathogenesis of the disease has been described [6,7]. We report an interesting case of the most rare (focal) type of the Takotsubo (stress) cardiomyopathy.

\section{Case Report}
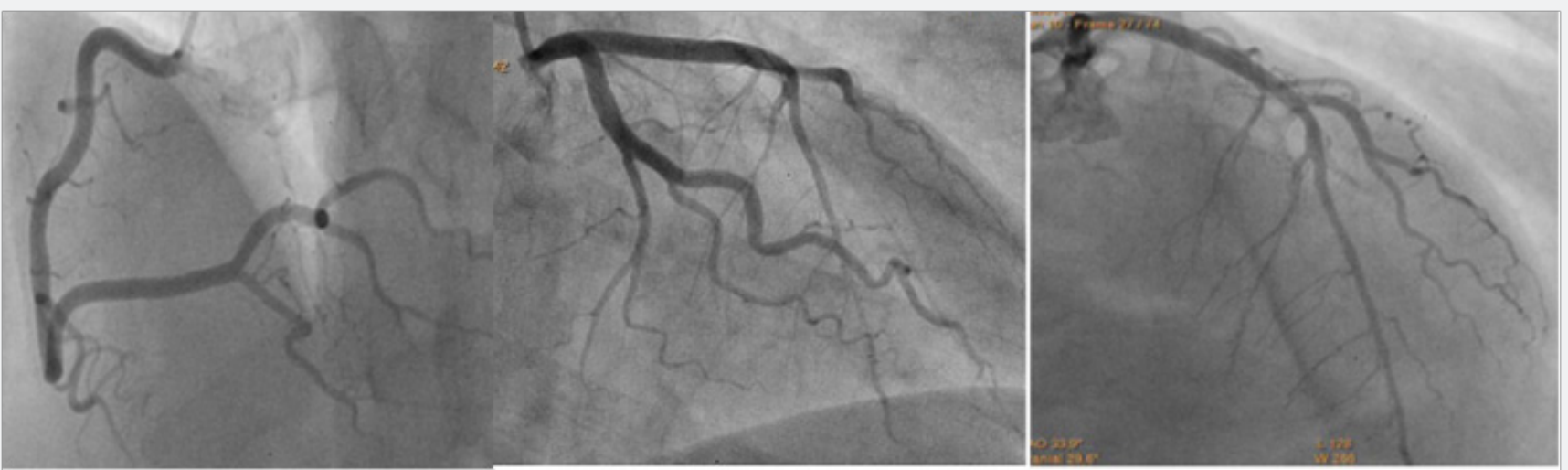

Figure 1: Right and left selective coronary angiograms showing right dominance and absence of any significant obstructive stenosis. 

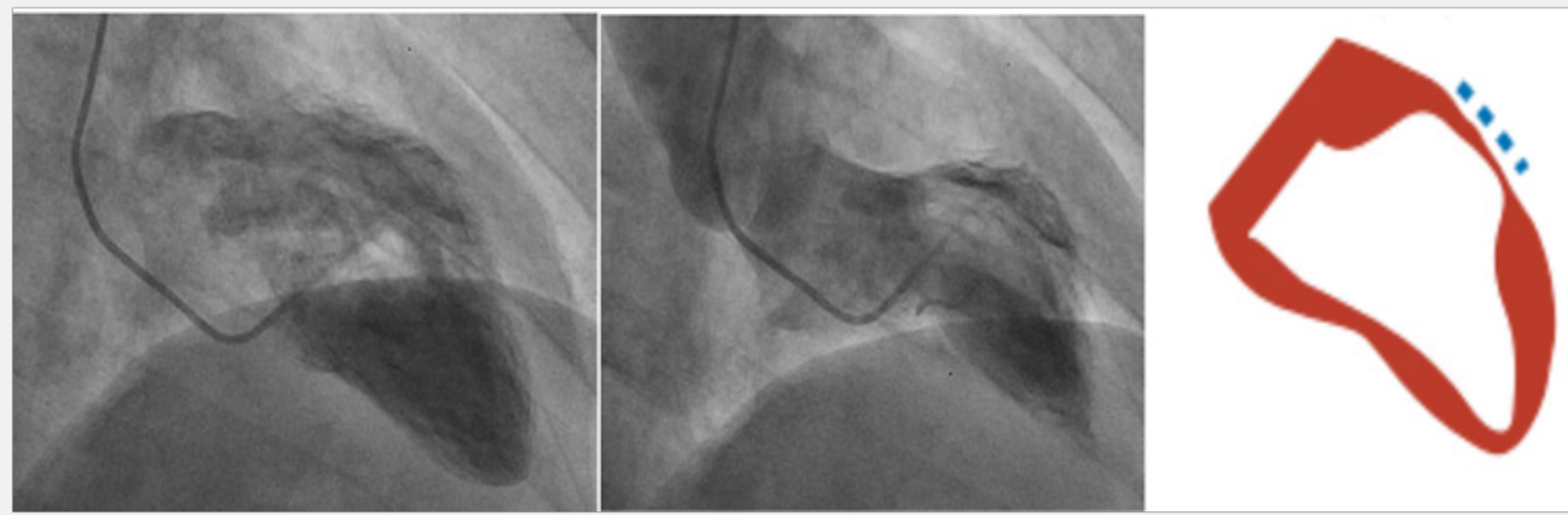

Figure 2: Left ventricle angiogram, in the $30^{\circ}$ right anterior oblique view, showing a focal (mid anterior wall) left ventricular systolic dysfunction (akinesia), compatible with the most rare (focal) type of Takotsubo (stress) cardiomyopathy.

A 45-years-old man, active, current cigarrete smoker and alcoholic, without any other relevant classic cardiovascular risk factors or co-morbidities. Due to recurrent sin copal episodes, without chest pain, he was conducted to the emergency department by his family. The serial resting electrocardiograms revealed interesting dynamic alterations: initially marked antero-lateral subepicardial ischemia; then, additional inferior

subepicardial ischemia; and, ultimately, it turned to the initial isolated antero-lateral subepicardial ischemia. There was a typical positive raising of the cardiac troponin. The clinical examination was unremarkable. He was then referred to the catheterization laboratory to an urgent invasive coronary stratification. Beyond a mild mid portion left anterior descending myocardial bridging, there were no significant coronary stenosis at any point (Figure 1). Surprisingly, it was found a focal (mid anterior wall) left ventricular systolic dysfunction (akinesia), compatible with the most rare (focal) type of TSC (Figure 2). Due to the absence of significant coronary artery disease, the patient was optimally medical managed, with aspirin, statin, angiotensin-convertingenzyme inhibitor and beta-blocker, without recurrence of sincopal episodes or any other related symptoms.

\section{Discussion}

Templin et al. [4] recently demonstrated that TSC represents an acute heart failure syndrome associated with a substantial risk for adverse events. There is an uneven sex distribution, with a female-to-male ratio of 9:1 [4,8]. TSC is predominantly preceded by emotional triggers, but it may also occur with physical triggers or even without any evident preceding factors [4-7], like in this case.

Of note, the coronary microcirculation is innervated by neurons that originate in the brain stem and mediate vasoconstriction, which supports the concept that myocardial stunning due to microvascular dysfunction among patients with takotsubo cardiomyopathy may be of neurogenic origin [9]. Since patients with TSC commonly present with symptoms similar to those of ACS, initial diagnosis and treatment in the emergency room remains challenging [4].

Therefore, early coronary angiography remains necessary to rule out an ACS. Notably, up to $15.3 \%$ of patients with TSC may have evidence of coexisting coronary artery disease on angiography [4]. This finding shows that the presence of coronary artery disease is not an exclusion criterion for the diagnosis of TSC [4].

Among the 1750 patients of The International Takotsubo Registry (www.takotsubo-registry.com), the most common was the apical type (81.7\%), followed by the midventricular type (14.6\%), the basal type (2.2\%) and the focal type (in only $1.5 \%$ of patients). The case reported here reproduces the most rare (focal) type of this condition.

TSC should be considered to be an acute heart failure syndrome, as reflected by the markedly increased levels of brain natriuretic peptide and left ventricular end-diastolic pressure. Consistently, systolic LV function was reduced to an even greater extent among patients with takotsubo cardiomyopathy than among those with an acute coronary syndrome [4].

The spectrum of TSC is wide and ranges from low to very high risk in the acute phase. The relatively rapid recovery of LV function and a selection bias of previous reports toward low-risk patients generated the misapprehension that it is a universally benign disease. This condition, however, represents an acute heart failure syndrome with substantial morbidity and mortality [4].

\section{References}

1. Sato HTH, Uchida T, Dote K, Ishihara M (1990) Tako-tsubo-like left ventricular dysfunction due to multivessel coronary spasm. In: Kodama K, Haze K, Hori M, eds. Clinical aspect of myocardial injury: from ischemia to heart failure. Tokyo: Kagakuhyoronsha Publishing 56-64.

2. Hurst RT, Prasad A, Askew JW III, Sengupta PP, Tajik AJ (2010) Takotsubo cardiomyopathy: a unique cardiomyopathy with variable ventricular morphology. JACC Cardiovasc Imaging 3(6): 641-649. 
3. Medeiros K, O'Connor MJ, Baicu CF, Fitzgibbons TP, Shaw P, et al. (2014) Systolic and diastolic mechanics in stress cardiomyopathy. Circulation 129(16): 1659-1667.

4. Templin C, Ghadri JR, Diekmann J, Christian NL, Bataiosu DR, et al. (2015) Clinical Features and Outcomes of Takotsubo (Stress) Cardiomyopathy. N Engl J Med 373(10): 929-938.

5. Tsuchihashi K, Ueshima K, Uchida T, Oh-mura N, Kimura K, et al. (2001) Transient left ventricular apical ballooning without coronary artery stenosis: a novel heart syndrome mimicking acute myocardial infarction: angina pectorismyocardial infarction investigations in Japan. J Am Coll Cardiol 38(1): 11-18.
6. Samuels MA (2007) The brain-heart connection. Circulation 116(1): 77-84.

7. Suzuki H, Matsumoto Y, Kaneta T, Sugimura K, Takahashi J, et al. (2014) Evidence for brain activation in patients with takotsubo cardiomyopathy. Circ J 78(1): 256-258.

8. Schneider B, Athanasiadis A, Stöllberger C, Pistner W, Schwab J, et al. (2013) Gender differences in the manifestation of tako-tsubo cardiomyopathy. Int J Cardiol 166(3): 584-588.

9. Cheung RT, Hachinski V (2000) The insula and cerebrogenic sudden death. Arch Neurol 57(12): 1685-1688.

\begin{tabular}{l} 
Your next submission with Juniper Publishers \\
will reach you the below assets \\
- Quality Editorial service \\
- Swift Peer Review \\
- Reprints availability \\
- E-prints Service \\
- Manuscript Podcast for convenient understanding \\
- Global attainment for your research \\
- Manuscript accessibility in different formats \\
( Pdf, E-pub, Full Text, Audio) \\
- Unceasing customer service \\
Track the below URL for one-step submission \\
https://juniperpublishers.com/online-submission.php \\
\hline
\end{tabular}

